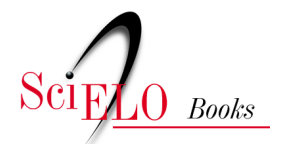

\title{
Parte II
}

\section{A mulher em situações de violência sob a ótica da saúde}

\author{
Romeu Gomes
}

\section{SciELO Books / SciELO Livros / SciELO Libros}

GOMES, R. A mulher em situações de violência sob a ótica da saúde. In.: MINAYO, M. C. S., and SOUZA, E. R., eds. Violência sob o olhar da saúde: infrapolítica da contemporaneidade brasileira [online]. Rio de Janeiro: Editora FIOCRUZ, 2003, pp. 199-222. ISBN: 978-65-5708-115-0. https://doi.org/10.7476/9786557081150.0009.

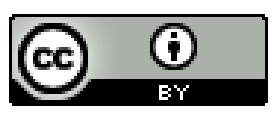

All the contents of this work, except where otherwise noted, is licensed under a Creative Commons Attribution 4.0 International license.

Todo o conteúdo deste trabalho, exceto quando houver ressalva, é publicado sob a licença Creative Commons Atribição 4.0.

Todo el contenido de esta obra, excepto donde se indique lo contrario, está bajo licencia de la licencia Creative Commons Reconocimento 4.0. 


\section{A Mulher em Situaçõés de Violência sob a Otica da Saúde}

Romeu Gomes

\section{INTRODUÇÃO}

$\mathrm{N}$

este capítulo, objetiva-se analisar discursos acerca da mulher em situações de violência, estabelecidos no campo da produção bibliográfica brasileira da saúde da década de 90 . Através dessa análise, pretendese problematizar as idéias mais recorrentes envolvidas na caracterização e nas formulações explicativas para a temática em questão.

De um modo geral, a discussão sobre a mulher em situações de violência aparece traduzida na expressão 'violência contra a mulher'. Grossi \& Aguinsky (2001) consideram que, em torno dessa temática, há muitos avanços no sentido de desnaturalizar os maus-tratos e a negação de direitos à mulher como algo 'normal' à condição feminina. No entanto, ainda segundo as autoras citadas, apesar dos esforços empreendidos, alguns descaminhos são percebidos nesse debate, dentre os quais é destacada a forma como são tratadas as discussões, muitas vezes perpassadas por forte conteúdo denunciativo, que pode ter como conseqüência a redução das dimensões do problema, deslocando-o da complexidade do real. Assim, propiciam também a perpetuação das práticas tutelares e a reificação dos processos de opressão que pretendem combater.

Schraiber \& D'Oliveira (1999) observam que a expressão 'violência contra a mulher' foi

cunhada pelo movimento feminista há pouco mais de vinte anos. A expressão refere-se a situações tão diversas como a violência física, sexual e psicológica cometida por parceiros íntimos, o estupro, o abuso sexual de meninas, o assédio de mulheres, o turismo sexual, a violência étnica e racial, a violência cometida 
pelo Estado, por ação ou omissão, a mutilação genital feminina, a violência e os assassinatos ligados ao dote, o estupro em massa nas guerras e conflitos armados. (Schraiber \& D’Oliveira 1999, p. 13)

Segundo as autoras, a temática em questão também pode ser vista da perspectiva de gênero, referindo-se, assim, a "sofrimentos e agressões dirigidos especificamente às mulheres pelo fato de serem mulheres" (Schraiber \& D'Oliveira 1999, p. 14).

Conforme observam Suárez \& Bandeira (2002), no final dos anos 70 e início dos anos 80 , no Brasil, presencia-se uma articulação do discurso feminista e de outros movimentos de mulheres em torno da crítica à 'violência contra a mulher'. Essa crítica, no fim do regime militar, era atravessada por denúncias à falta de propostas democráticas. Diante das inúmeras reivindicações nesse campo, foram implantadas as Delegacias Especializadas no Atendimento à Mulher (Deams). As autoras citadas ressaltam que, embora as Deams tenham imperfeições, são instituições governamentais que expressam a configuração de um espaço público em que se desenvolve o discurso acerca dos direitos das mulheres e de seu tratamento eqüitativo perante as denúncias de situações de violência.

Ainda para essas autoras, essa 'politização da violência contra a mulher' também teve reflexos no campo das ciências humanas, expressos, principalmente, numa produção teórica e numa reflexão acerca das formas de violências disseminadas na sociedade e traduzidas nos conflitos interpessoais.

Encontram-se, na década de 90, repercussões dos marcos históricos, mencionados antes, na produção bibliográfica do campo da saúde, que vão abordar muito mais questóes relacionadas à 'violência contra a mulher' do que as que tratam da relação 'violência e mulher'. Como se poderá ver posteriormente, a abordagem da 'violência contra a mulher' pode ter como conseqüência a redução do debate à pura e simples vitimização, ao passo que situar a discussão em torno da relação 'violência e mulher' pode, dentre outros aspectos, considerar a mulher a partir do status de sujeito de direitos.

Estudos realizados em vários países americanos revelam que os níveis de violência doméstica contra mulheres são altos na região. "Entre $30 \%$ e $50 \%$ das mulheres adultas com parceiros são vítimas de maus-tratos psicológicos a cada ano, enquanto $10 \%$ a $35 \%$ sofrem violência física, segundo indica a maioria dos estudos" (Buvinic et al., 2000, p. 19).

Heise Pitanguy \& Germain (1994) observam que a principal forma endêmica de violência contra a mulher se expressa na figura da esposa 
agredida, mais precisamente na mulher agredida pelos seus parceiros íntimos. Com base em 35 estudos realizados em vários países, as autoras constatam que de um quarto até mais da metade de relatos de mulheres indica agressão física cometida pelo parceiro atual ou anterior.

Além dos diversos tipos de maus-tratos, a mulher também é alvo da violência estrutural. Um dos indicadores dessa situação é a comparação de sua renda com a do homem. Dados do Censo do IBGE de 2000 mostram que, apesar de as mulheres terem vida média mais elevada do que os homens, assumirem cada vez mais o comando das famílias e apresentarem uma ligeira vantagem em termos de alfabetização, sua renda continua sendo inferior à dos homens, representando $71,5 \%$ da renda masculina ${ }^{1 .}$

Junto à magnitude dos maus-tratos sofridos pelas mulheres, aspectos relacionados ao significado desses maus-tratos, bem como valores e crenças a eles associados, são tão importantes quanto a extensão do problema. Nesse sentido, esta análise volta-se sobretudo para a forma como a produção acerca do assunto aborda tais aspectos.

Finalmente, assinala-se que, junto ao fato de a produção enfocar mais a 'violência contra a' mulher, não se pode perder de vista a relação 'violência e mulher' que se estabelece no campo da saúde. Assim, busca-se no presente trabalho compreender se a produção, além de olhar a mulher como vítima, também a considera como sujeito que se insere num conjunto de relações reconhecidas como violentas.

\section{Metodologia}

A presente análise baseou-se numa pesquisa bibliográfica realizada pelo Centro Latino-Americano de Estudos sobre Violência e Saúde Jorge Careli (Claves/Ensp/Fiocruz), com a parceria do CNPq. Essa investigação teve o "objetivo de estabelecer um panorama geral sobre o estado da arte acerca da temática violência no campo da saúde" (Souza \& Minayo, 2001).

Dentro dessa pesquisa, foram selecionadas as fontes bibliográficas brasileiras referentes à temática 'violência e mulher', produzidas no campo da saúde, na década de 90 . Ao todo, foram analisadas 38 fontes, sendo 22 artigos, 12 dissertações de mestrado, dois capítulos de livro, uma tese de doutorado e um livro.

Inicialmente procurou-se dar um tratamento quantitativo às fontes, caracterizando cada uma delas a partir das seguintes variáveis: área de

\footnotetext{
$\overline{{ }^{1} \text { Dados obtidos no site www }}$ ibge. govbr em novembro de 2002.
} 
produção; sexo do primeiro autor; método utilizado; posição da mulher diante da violência; formas de violência; referencial teórico utilizado na explicação da violência contra a mulher; abordagem da saúde perante a violência, e proposta de prevenção. Utilizamos esse tratamento apenas para compor um quadro sobre a produção bibliográfica em geral.

Consideraram-se as seguintes áreas que compõem o campo da saúde: enfermagem; medicina (envolvendo obstetrícia, ginecologia e medicina legal); saúde coletiva (envolvendo saúde pública e epidemiologia); e saúde mental (envolvendo psicologia, psiquiatria e psicanálise).

No que se refere à metodologia utilizada nos trabalhos, levou-se em conta a seguinte classificação: ensaio; estudo de caso clínico; estudo descritivo; estudo epidemiológico descritivo ou analítico; estudo qualitativo; revisão bibliográfica; revisão teórica; estudos quantiqualitativos/interdisciplinares; estudos baseados em oficinas e seminários.

Na variável 'posição da mulher diante da violência', utilizou-se a seguinte classificação: a mulher vista como vítima; a mulher vista como agressora e a mulher vista, simultaneamente, como vítima e agressora.

Nesse primeiro momento da análise, distribuíram-se as fontes em relação a essas variáveis. Para isso, foi organizado um banco de dados em Dbase III Plus e trabalhou-se com freqüências simples e relativas e análise bivariada utilizando Programa Epi-Info 6.0.

Após essa etapa, fez-se uma análise dos conteúdos das fontes, buscando encontrar os núcleos de sentido dos textos, entendendo esses núcleos como "categorias empíricas que povoam o campo semântico definidor do conceito, das causas, das associações e da significância do fenômeno (...)" (Gomes et al., 1999, p. 173). À medida que se identificavam os núcleos de sentido de cada produção, problematizavam-se as idéias neles inseridas, e, saindo-se do plano apenas descritivo, trabalhou-se no nível interpretativo. Formularam-se algumas questões a serem respondidas a partir da compreensão de cada trabalho. Tais perguntas permitiram caminhar do texto para o subtexto ou do nível explícito no texto para o que estava implícito nas fontes.

Assim, cada fonte foi submetida aos seguintes questionamentos: Quais são as explicações para a violência cometida contra a mulher? Como essa violência se expressa? Qual é o papel atribuído à mulher nas situações de violência? Como são pensadas as implicações das discussões acerca do assunto no campo da saúde? Nem todas as fontes dedicavam espaço a todos esses aspectos, no entanto, nesta discussão foi considerado o conjunto delas. 


\section{A Produção em Números}

O conjunto da produção acerca das relações violência-saúde no campo da saúde revela alguns índices numéricos que podem, de certa forma, fornecer um quadro de referência para a sua análise. Nesse conjunto, como pode se visto no Quadro 1, a área da saúde coletiva destaca-se como a que mais abordou as relaçōes entre violência, mulher e saúde.

\section{Quadro 1 - Distribuição da Produção por Área}

\begin{tabular}{|c|c|c|c|}
\hline Área & Autores & $\mathrm{N}$ & $\%$ \\
\hline Enfermagem & $\begin{array}{l}\text { Corrêa (2000); Kantorski \& Moreira (1997); } \\
\text { Leite (1999); Moura \& Oliveira (2000); } \\
\text { Santos (2000); Xavier (1999). }\end{array}$ & 6 & 16 \\
\hline Medicina & $\begin{array}{l}\text { Beissman (1994); Bergamo (1998); } \\
\text { Campos et al (1994); Cohen \& Matsuda (1991); } \\
\text { D’Oliveira (1996); Faundes et al (2000); } \\
\text { Priante (2000), Santos (1997). }\end{array}$ & 8 & 22 \\
\hline Saúde Coletiva & $\begin{array}{l}\text { Albuquerque et al. (1998); Cabral (1999); } \\
\text { Deslandes et al. (2000); Giffin (1994); } \\
\text { Jong (2000); Leitão (1991); Meneghel et al. (2000); } \\
\text { Noronha \& Daltro (1991); Reichenheim et al (2000); } \\
\text { Schraiber et al. (2000); Suárez et al. (1999); } \\
\text { Tavares (2000); Tuesta (1997). }\end{array}$ & 15 & 40 \\
\hline Saúde Mental & $\begin{array}{l}\text { Braghini (2000); Cardoso (1996); Martins (1997); } \\
\text { Moreira (1999); Paula (1995); Santos (1997); } \\
\text { Simão et al. (1997); Tetelbom et al. (1991); } \\
\text { Vicente (1999). }\end{array}$ & 9 & 22 \\
\hline Total & & 38 & 100 \\
\hline
\end{tabular}

Embora a produção tenha se distribuído de forma irregular, ao longo da década, observa-se que, nos dois últimos anos (1999 e 2000), houve uma concentração de trabalhos, perfazendo $54 \%$ de todo o conjunto. Ao analisar a associação entre área e ano de produção, pode-se constatar que enfermagem e saúde coletiva contribuíram para tal concentração, uma vez que a maior parte de seus textos refere-se aos dois últimos anos da década. 
Em $78 \%$ da produção, o primeiro autor era do sexo feminino. Não se encontra uma associação significativa entre essa constatação e a área disciplinar. Em outras palavras, o fato de, no conjunto das áreas, por exemplo, estar presente a enfermagem, que é predominantemente exercida por mulheres, não influenciou o predomínio de autores do sexo feminino.

No que se refere à metodologia empregada pelos autores, há o predomínio da abordagem qualitativa, representando $30 \%$ de toda a produção. Os dois últimos anos estudados (1999 e 2000) foram os que acumularam trabalhos com essa abordagem, concentrando cerca de $80 \%$ de todas as fontes. Isso indica uma crescente preocupação com significados atribuídos às relações entre violência e mulher.

A violência sexual foi o tipo mais analisado de violência, presente em 13 estudos, representando $34 \%$ de toda a produção. Destaca-se que a violência física foi estudada em oito trabalhos (21\%) e a violência psicológica, em cinco trabalhos (13\%). Sete estudos (18\%) abordaram a temática sem dar ênfase a uma ou mais formas de violência.

A visão da mulher apenas como vítima é predominante nos estudos. No conjunto das fontes, 26 (68\%) correspondem a essa abordagem. Em 12 trabalhos (32\%), a mulher é considerada tanto como vítima quanto como agressora, sendo que a metade desses estudos provém da área da saúde mental.

Em relação à forma como explicam a violência contra a mulher, identificam-se as seguintes situações: 19 fontes (50\%) a consideram como uma violência de gênero; 11 (28,9\%) não se propõem explicar o porquê da ocorrência da violência contra mulher; três $(7,9 \%)$ associam-na a aspectos socioestruturais em geral; um $(2,6 \%)$ conclui que a literatura costuma relacionar, de forma genérica, a violência ao alcoolismo; um $(2,6 \%)$ apresenta uma relação da violência com a afetividade existente entre casais; e um $(2,6 \%)$ destaca a omissão de políticas públicas como um fator que concorre para a existência desse tipo de violência.

Ao se fazer uma relação entre a variável 'explicação da violência contra mulher' com as variáveis 'área da produção', 'ano de publicação e método', verifica-se uma associação entre essas variáveis. A análise revelou que a forma de explicar a violência contra a mulher a partir da violência de gênero: (a) concentra-se na área da saúde coletiva, (b) está presente predominantemente nos anos de 1999 e 2000 e (c) está associada aos estudos que utilizam uma abordagem metodológica qualitativa.

Representando 74\% do conjunto, 28 trabalhos tecem considerações sobre o impacto da violência na saúde da mulher e dez (26\%) não o fazem. Dentre os 28 estudos que refletem as repercussões das relações violênciamulher na saúde, 22 tratam de agravos à saúde decorrentes dessas relaçóes 
e seis fazem uma discussão sobre o fato de o setor não abordar adequadamente tais relações.

Para finalizar a caracterização da produção analisada, observa-se que 27 trabalhos (71\%) não explicitam uma proposta de prevenção. Dos 11 estudos que mencionam tal tipo de proposta, oito concentram-se nos anos de 1999 e 2000, revelando que a discussão acerca dessa questão é recente.

\section{A Violência Contra a Mulher como Reflexo das Relações DE GÊNERO}

Uma das tendências da produção bibliográfica acerca da violência contra a mulher, realizada na década de 90 , é considerar tal temática a partir da perspectiva de gênero. Essa perspectiva é acessada, principalmente, para explicar a ocorrência de maus-tratos cometidos contra a mulher e a violação de seus direitos. Assim, nas relações entre os gêneros masculino e feminino encontrar-se-íam as raízes explicativas para situações adversas à mulher.

O movimento feminista, no final dos anos 60 , destacou-se em denunciar casos violentos contra a mulher, dando visibilidade a essa realidade que, até então, permanecia no âmbito privado. O termo 'gênero' passou a ser utilizado pelas feministas para traduzir as diversas formas de interação humana, buscando conceituá-lo como uma 'forma de legitimar e construir as relações sociais'. Dentro dessa abordagem, as relações violentas, em específico, e as relações sociais, em geral, estabelecidas entre homens e mulheres, seriam vistas a partir das diferenças culturais e não das especificidades biológicas atribuídas aos gêneros masculino e feminino (Tavares, 2000).

A abordagem de gênero, que surgiu há mais de três décadas, conseguiu progressivamente consolidar-se como modelo explicativo hegemônico para a ocorrência da violência contra a mulher. Essa afirmação sustenta-se no fato de tal modelo, na virada do século XX para o XXI, ainda ser uma tendência explicativa majoritária na produção especializada sobre a temática em questão.

Assim, a violência sofrida pela mulher é entendida como uma violência de gênero (D'Oliveira \& Schraiber, 1999), estruturada por um 'padrão de relações sexuais hierárquico' (Meneguel et al., 2000), no qual as mulheres sofreriam violências 'pelo fato de serem mulheres' (Schraiber \& D'Oliveira, 1999). Isso configuraria um reflexo da 'manutenção de desi- 
gualdades e hierarquias existentes para garantir a obediência e a subalternidade de um sexo sobre outro' (Corrêa, 2000), expressando um 'sistema social desigual e injusto' (Kantorski et al., 1997).

Nessas relações, 'normatizadas pela falocracia' (Xavier, 1999), ideologicamente legitima-se a dominação masculina à qual a mulher pode estar submetida, 'desde sua infância' (Tetelbom et al., 1991). Assim, tanto no âmbito da violência do comportamento individual quanto na instância da violência estrutural, a partir de definições sociais, à mulher se atribui 'um papel secundário, limitando a sua cidadania' (Deslandes et al., 2000; Jong, 2000; Santos, 1997).

As explicações 'da universalização da opressão da mulher', construídas pela perspectiva de gênero, são teoricamente embasadas no 'conceito de patriarcado, na teoria marxista e nos estudos da psicanálise'. No patriarcado, a 'opressão feminina se explica a partir da apropriação masculina do labor reprodutivo das mulheres' e/ou da 'reificação sexual das mulheres pelos homens'. As teorias marxistas procuram articular 'sistemas de dominação de classe com sistemas de dominação de gênero'. Já a psicanálise busca encontrar 'as raízes das relaçóes de gênero, na construção da subjetividade'. Nesses referenciais teóricos, destaca-se o papel histórico do 'movimento feminista', que, diante da opressão masculina, trouxe à cena um novo sujeito social: as mulheres (D'Oliveira, 1996).

No desempenho dos papéis feminino e masculino, 'arranjos estereotipados estruturam a intimidade entre os gêneros e os dilemas das relações podem culminar em violência' (Vicente, 1999). Isso significa que, quando os mecanismos sutis de controle não funcionam, o uso de violência seria acionado para garantir a hierarquização entre os sexos (Braghini, 2000; Noronha \& Daltro, 1991). Os maus-tratos físicos são uma das expressões desse tipo de controle. Outra forma de controle é exercida através da 'sexualidade que atua sobre as mentes e os corpos das mulheres, implicando uma associação entre sexualidade, poder e violência masculina' (Giffin, 1994).

No diálogo entre a produção bibliográfica sobre a violência contra a mulher no campo da saúde e a área das Ciências Sociais, destaca-se a contribuição das idéias de Pierre Bourdieu na ampliação do debate da temática em pauta. Esse autor, no final dos anos 90 , teve uma obra publicada no Brasil que aborda a assimetria de gênero (Bourdieu, 1999).

Nessa obra, Bourdieu observa que a relevância do tema da sexualidade ocorre a partir de significaçóes sociais que se inserem num cenário de regras de dominação que presidem a vida social atribuídas ao corpo. No interior dessas regras, destaca-se a oposição entre masculino e femini- 
no, na qual se revela uma dominação de sexo, que não se instaura pela fisiologia ou pelo psiquismo, mas sim por uma ordem simbólica coletiva.

Nesse sentido, a ordem social opera como uma imensa máquina simbólica, ratificando a dominação masculina sobre a qual se ancora. Dessa forma,

diferença biológica entre os sexos, isto é, entre o corpo masculino e o corpo feminino e, especificamente, a diferença anatômica entre os órgãos sexuais, pode, assim, ser vista como justificativa natural da diferença socialmente construída entre os gêneros e, principalmente, da divisão social do trabalho. (Bourdieu, 1999, p. 20)

A partir dessa construção social, a incorporação da dominação ocorre ou é reforçada pela violência simbólica, efetivada não só para além da consciência e da vontade de quem por ela é atingido, mas também por uma relação de cumplicidade que tanto pode contribuir para a sua perpetuação como para a sua transformação.

Assim, a inferioridade e a exclusão da mulher, ratificadas e ampliadas pelo sistema mítico-ritual, que se configura como um princípio de divisão de todo o universo, não é mais que a assimetria fundamental instaurada entre o homem e a mulher. Isso faz com que as mulheres só sejam "vistas como objetos, ou melhor, como símbolos cujo sentido se constitui fora delas e cuja função é contribuir para a perpetuação ou o aumento do capital simbólico em poder dos homens" (Bourdieu, 1999, p. 55).

No cenário da dominação masculina, as vítimas não são apenas as mulheres. Nele, os homens também estão aprisionados, sem que se percebam como vítimas da representação dominante. Seguindo esse raciocínio, o "privilégio masculino é também uma cilada e encontra sua contrapartida na tensão e na contensão permanentes, levadas por vezes ao absurdo, que impõe a todo o homem o dever de afirmar, em toda e qualquer circunstância, sua virilidade" (Bourdieu, 1999, p. 64). No exercício de seus papéis, o homem é a todo o momento testado em situações em que virilidade e violência se mesclam num espaço que está "fora de todas as ternuras e de todos os enternecimentos desvirilizantes do amor (...)" (Bourdieu, 1999, p. 66).

Nesse processo de testagem ao qual o homem é submetido, o autor chama atenção para o fato de que o que é tido como "coragem" pode estar enraizado numa covardia, ou seja, pode se basear no medo "viril" de ser excluído do mundo dos "homens" sem fraqueza. "A virilidade, como se vê, é uma noção eminentemente relacional, construída diante dos outros 
homens, para os outros homens e contra a feminilidade, por uma espécie de medo do feminino, e construída, primeiramente, dentro si mesmo" (Bourdieu, 1999, p. 67).

As relaçōes de gênero podem servir de base para uma consistente explicação sobre as relações violência-homem-mulher. No entanto, para que esse modelo explicativo avance, é preciso, antes de tudo, que a palavra 'gênero' seja compreendida a partir de uma perspectiva relacional. Nem sempre isso ocorre. Grande parte dos autores analisa o problema a partir de mão única, ou seja, a direção da violência do homem para a mulher. Alguns, utilizando a observação de Schraiber e D'Oliveira (1999), não conseguiram deslocar a abordagem do feminino para se pensar acerca de estratégias de conhecimento e de intervenção que abordem os homens, numa dimensão relacional.

\section{Violência Sexual como Expressão da Violência Contra a MULHER}

No conjunto das fontes analisadas, a forma de expressão predominante é a de natureza sexual. Os autores que privilegiam a violência sexual como expressão da violência cometida contra a mulher o fazem por diferentes motivos. Um deles é por causa do campo empírico em que se inserem seus estudos. Aí destacam-se pesquisas realizadas em Institutos Médicos Legais de diferentes cidades (Bergamo, 1998; Campos et al., 1994; Cohen \& Matsuda, 1991; Priante, 2000) e investigação desenvolvida em Delegacia de Polícia de Defesa da Mulher (Santos, 1997). Nesse campo de investigação, em que as questões sexuais são recorrentes, ressaltam-se os seguintes dados: predomínio de vítimas com menos de 18 anos de idade; recorrência de casos de estupros, tendo como agentes da violência pessoas próximas da vítima ou com grau de parentesco.

Outra possível explicação para alguns estudos focarem a violência sexual por vezes está relacionada ao fato de ela refletir outras modalidades de violência. Autores, a exemplo de Kantorski, Moreira \& Luz. (1997) e Schraiber \& D’Oliveira (1999), sinalizam em suas análise que a violência sexual se encontra imbricada com outros conteúdos de violência, como os de ordem moral, física e psicológica.

A violência sexual costuma ser mencionada no conjunto das fontes a partir de situações com diferentes nuanças que vão desde atos com contato físico violento até aqueles que ocorrem sem contato físico. No entanto, 
no conjunto dos estudos, o estupro ocupa posição de destaque (Cohen \& Matsuda, 1991; Kantorski, Moreira \& Luz., 1997; Suárez, Machado \& Bandeira, 1999 e Santos, 1997b).

Os autores registram uma ocorrência significativa de estupro. Bandeira (1999) observa que, no conjunto de 25.589 crimes denunciados e registrados pela DEAM/DF, no período de 1987 a 1997, 2.092 se relacionaram a crimes sexuais, sendo que $38,86 \%$ foram estupros e $61,14 \%$ foram estupros conjugados com outros crimes. A referida autora observa, ainda, que os "crimes de estupro ocorrem em todos os lugares e são praticados por indivíduos de qualquer segmento social" (Bandeira, 1999, p. 453).

Para além dos números, essa temática configura-se em espaço privilegiado para se discutir a violência nas relações de gênero. No imaginário social o estupro provoca atitudes ambíguas. É visto como um crime hediondo, em relação à vítima, e, ao mesmo tempo, é percebido como um fato banal (Bandeira, 1999).

O estupro parece ser o lugar onde se exercita a identidade masculina por espelhamento: o corpo 'subjugado' da mulher 'reassegura' essa identidade, reafirmand o o 'caráter sacrificial' dos corpos femininos. Nesse sentido, a iniciativa masculina e a recusa inicial feminina podem compor o 'jogo sexual', "confundindo-se, assim, estupro com 'o jogo normal das relações sexuais'. É nessa fala discursiva que as pretensas vítimas são culpabilizadas" (Suárez et al., 1999, p. 290).

Bourdieu (1998) também observa que o ato sexual é representado como um 'ato de dominação, um ato de possessão, uma tomada da mulher pelo homem'. Nessa representação, está presente uma topologia em que 'o homem está acima, em cima, e a mulher abaixo, embaixo'. A idéia desse autor poderia também servir para explicar o estupro como emblema da dominação masculina.

Ampliando a discussão acerca do estupro, pode-se observar que esse tema tem uma história, em que se vão percebendo mudanças culturais na forma de olhá-lo. A obra de Vigarello (1998) é bastante ilustrativa nesse sentido, pois, para ele a forma de enxergar o estupro confunde-se com a maneira de se ver a mulher. A suspeição colocada a priori diante da queixa da mulher estuprada revela a imagem de que ela cede 'voluntariamente' em virtude da sua 'fraqueza' ou 'inferioridade'. Para ele, atualmente, mudanças culturais são percebidas quando se observa o aumento de queixas. Uma das explicações do autor para esse aumento é a maior conquista de igualdade com os homens, que torna mais intoleráveis à sociedade antigas violências bem como o modelo de dominação que elas expressam. Assim, "as mudanças são paralelas às dos sistemas de opressão exercidos sobre a 
mulher, a sua permanência, seu refinamento, seus deslocamentos" (Vigarello, 1998, p. 9).

Diante do estupro, em específico, e à violência sexual, em geral, mais uma vez tem de ser retomada a discussão das relações masculino e feminino. Não basta apenas proteger as mulheres dos homens estupradores e violentadores. É preciso que novos modelos de identidade sexual sejam trabalhados no sentido de excluir a dominação como referência identitária do masculino e a subjugação como uma pertença ao feminino.

\section{A Vitimização da Mulher}

A própria expressão 'violência contra a mulher', de certa forma, aponta para a tendência de se focalizar predominantemente a vitimização feminina. As fontes deste estudo reforçam essa tendência, ao revelar que, em geral, a mulher é considerada como vítima. Várias delas apresentam dados em que a mulher é mais vítima do que agressora. A exemplo disso, destacamos Giffin (1994), Simão et al. (1997), Schraiber et al. (2000) e Tavares (2000).

No sentido de melhor problematizar a vitimização, orienta-se esta análise para as fontes que não reduzem sua perspectiva. Eleger tais fontes, ainda que em termos de extensão represente um pequeno recorte, permite apontar a possibilidade de ver o problema sob outra perspectiva. Por isso, desenvolve-se a discussão a partir das seguintes questões: O que as fontes que fogem do lugar-comum (ver a mulher como vitima) abordam? Como avançar na discussão para ir-se além da vitimização feminina?

Na comparação entre gêneros e agentes da violência, há poucos estudos que se voltam para as formas de violência expressas por homens e mulheres. Suárez, Machado \& Bandeira (1999), caminhando nessa direção, destacam que, embora as mulheres sejam percebidas e tratadas como vítimas e os homens como agressores, há informações norte-americanas que atestam que a criminalidade masculina e a feminina assemelham -se nas categorias mais freqüentes, a exemplo do furto, roubo e dirigir intoxicado(a), e diferenciam-se mais no que se refere ao homicídio e ao estelionato.

No caso brasileiro, ressalta-se a investigação de Leite (1999), com 50 mulheres prisioneiras, que indica os principais crimes femininos, com suas respectivas freqüências: tráfico de entorpecentes (23); homicídios (9); furto (6); estelionato (6) e roubo (3). Esses dados, de uma certa forma, 
confirmam-se em pesquisa realizada com 89 mulheres que cometeram crimes (Almeida, 2001), na qual destacam-se os seguintes crimes com suas respectivas freqüências: tráfico e/ou consumo de drogas (50); roubo (20) e homicídio qualificado (10).

Dados acerca dos anos de 1976 e 1997, de um presídio feminino do Rio de Janeiro, revelaram que "o tráfico de drogas lidera como o delito mais freqüente e de maior crescimento nesse período. Não se pode deixar de apontar o aumento significativo na participação de mulheres nos roubos e em seqüestros, delitos considerados graves" (Constantino, 2001, p. 43).

Ao se discutir sobre a especificidade do crime feminino, duas idéias são recorrentes. Uma delas refere-se ao fato de que as mulheres praticam menos crimes do que os homens, e a outra diz respeito à baixa gravidade dos delitos femininos. Concorrendo com essas idéias também há a constatação de que as mulheres que chegam a se envolver em delitos, em geral, sofreram ao longo de sua vida inúmeros agravos físicos e emocionais (Constantino, 2001, p. 42).

Almeida (2001), refletindo sobre as estatísticas que revelam um número mínimo de mulheres que matam em relação aos homens, adverte que isso corresponde

à realidade da mulher que, historicamente, foi "escondida" no espaço privado. Assim, a mulher comete menos crimes dessa natureza por ter sido socializada para o confinamento ao mundo privado, para ser mãe e esposa, cujas características de docilidade $\mathrm{e}$ fragilidade lhes foram atribuídas para cumprir seu papel de dedicação ao lar. A mulher foi educada para o "doce" lar, lugar da passividade e benevolência, e o homem para o mundo "cão", lugar do trabalho e da competição, onde deveria ser forte e viril para, de lá, retirar o sustento de sua família. (Almeida, 2001, p. 21)

Sobre o fato de os crimes praticados por mulheres serem menos graves do que os praticados por homens, as certezas nem sempre se sustentam. No caso do tráfico de drogas, por exemplo, isso não é observado. Estudo revela que "quando as adolescentes alcançam posições mais altas na hierarquia do mercado ilegal de drogas ('segurança', 'gerente' e até mesmo 'dono') precisam se submeter às regras gerais da organização, não havendo diferenças por gênero" (Constantino, 2001, p. 43).

Martins (1997) também observa que os crimes de natureza passional não se reduzem a uma classe socioeconômica, nem a um tipo de gênero. São crimes que se configuram como desfechos de uma trama que tem como origem dramática o clima passional que regula as relações de poder entre os sexos. Neles, os agressores podem ser homens ou mulheres. 
Ainda na discussão sobre as especificidades da violência entre os gêneros, um estudo traz dados que servem para uma reflexão sobre os preconceitos subjacentes a essa discussão. Trata-se de uma revisão bibliográfica realizada por Tetelbom e colaboradores (1991). Com base na literatura, os autores observam que o tipo de incesto entre "mãe-filho é considerado o tipo mais patológico, sendo freqüente sua associação com a psicose" (Tetelbom et al., 1991, p. 145). Esse dado, no mínimo, deve ser estranhado. Por que, quando é a mulher quem abusa, o incesto é o mais patológico? Será que o abuso do pai para a filha encontra-se mais naturalizado a ponto de o agressor ser considerado menos psicótico? Será que o fato de haver mais pais do que mães que cometem o incesto faz com que o menos freqüente seja classificado como anormal? Normal seria o mais comum? Se for apenas uma questão de estatística, por que se liga um determinado tipo à psicose? Essas questões ajudam avançar na discussão sobre as relações de gênero e violência.

Os autores concluem, ainda, que "é característica normal de toda menina ser sedutora, ter fantasias sexuais com o pai e sentimentos de rivalidade com a mãe" (Tetelbom et al., 1991, p. 148). Diante dessa conclusão, cabe outra reflexão relacionada a questões de gênero. Será que as imagens culturais das identidades masculinas não contribuem para que não se perceba a sedução entre os meninos? Ou seja, dá para concluir que, em alguns estudos de gênero, um tipo de violência simbólica, entranhada e culturalizada, permanece presente.

Ao estabelecer-se diálogo entre as fontes de estudo e outras obras das ciências sociais consultadas, podem-se apontar aspectos que servem à discussão da irredutibilidade da mulher ao papel de vítima. Essa visão tem origem, sobretudo, no campo do direito, no qual ou se é vítima ou se é agressor. Esse tratamento pode, de uma certa forma, refletir a construção social do feminino como carente, passivo e dependente (Schraiber \& D’Oliveira, 1999).

Em primeiro lugar, observa-se que a temática 'mulher em situação de violência' aponta a possibilidade de problematizar posições agressor/ vítima numa perspectiva de gênero. As dissociações entre agressor-homem e vítima-mulher poderão ajudar nessa discussão. Significa, então, considerar que as mulheres também podem ser agentes de violência, ainda que venham exercer esse papel de forma diferente da do homem (Saffioti, 2002).

Segundo as fontes deste estudo, ser agressor ou vítima pode estar relacionado a "encenações dos papéis que, conforme o imaginário de gênero, cabem às mulheres e aos homens desempenhar" (Suárez et al., 1999, p. 280). 
Essa encenação que leva as mulheres a desempenharem o papel de vítima e o homem, o de agressor, pode ser mais discutida a partir da violência simbólica. Nesse sentido, a dominação masculina - entendida do prisma de um poder simbólico que se produz e reproduz - contribuiria para que a virilidade fosse associada à idéia de agressor. Em contrapartida, o papel feminino se conformaria na servidão à essa dominação e, em resposta à figura do agressor, caberia à mulher ser vista como vítima. No entanto, a construção do poder simbólico só é possível com a colaboração dos que a ele se submetem. Evidentemente que essa submissão não é voluntária, e a cumplicidade com esse poder não é consciente (Bourdieu, 2001).

Pode-se caminhar na direção da mudança desse cenário tomando-se como referência o status de sujeito de direitos da mulher. Isso significaria entendê-la não como ser incompleto que necessitaria de uma tutela especializada (Schraiber \& D'Oliveira, 1999) e/ou reduzida à condição de vítima (Gomes et al., 1999).

A atuação na construção de modelos que possam contribuir para que as mulheres sintam-se como sujeitos diferenciados na relação com os homens rompe com mitos e crenças que contribuem para a manutenção da violência. Isso significaria a compreensão das mulheres como autoras de sua história. Nessa construção de sujeitos autônomos, elas não mais se reduzirão ao desempenho do papel de vítima (Vicente, 1999).

A partir dessa perspectiva, será possível compreender que as mulheres não matam apenas por ciúmes ou por sofrerem maus-tratos. Matam também inimigos, desafetos que lhes despertam o desejo de vingança ou de destruição do outro. A mulher também é violenta. Sobretudo, tal aceitação colabora para um projeto de autonomia social a ser atravessado nos desempenhos dos papéis de gênero (Almeida, 2001).

Seguindo nesse raciocínio, da mesma forma que o aumento da taxas de delinqüência é considerado um índice de 'desenvolvimento' nos países do Terceiro Mundo, a taxa de delinqüência feminina pode ser considerada como uma indicação de liberação da mulher (Boulding, 1981). A violência, nesse caso, embora negativa, teria uma certa faceta de positividade, na medida em que denotaria uma busca de autonomia por parte da mulher. Mas será que esse índice negativo deveria ser usado como sinal de liberação?

Contribuindo para o avanço da discussão, são importantes as considerações de Almeida (2001) em torno da idéia de que a violência em si não constitui um meio positivo para fins de transformação social para a liberdade. A autora chama a atenção para o fato de a violência ser uma ação destrutiva. No entanto, considera que pode se apresentar como 
construtiva, ao indicar a existência do estado de caos, de permanente conflito, de desigualdade, de discriminação e de exclusão. Mesmo considerando essas duas faces, conclui:

A violência não é ética, não leva à libertação de todas as mulheres, nem institui um movimento feminista para alcançar o poder através de sua prática. As mulheres agentes desses ilícitos não são revolucionárias da questão feminina. Algumas tentam ser justiceiras (...), mas continuam presas à contradição do ser feminina, ao mesmo tempo domesticada, fragilizada e liberta, valente. (Almeida, 2001, p. 186)

Acredita-se que algumas fontes estudadas, embora tenham apenas esboçado esse debate, na década de 90 , destacam-se por terem trilhado outras vias para se refletir sobre a temática 'mulher em situações de violência'.

\section{Implicaçōes para o Campo da Saúde}

Vários autores, a exemplo de D'Oliveira e Schraiber (1999) e Moreira (1999), fazem uma reflexão sobre as conseqüências da violência tanto no campo da saúde física quanto no da mental, sem especificar tipos de agravos.

Os autores que abordam os maus-tratos físicos, como Mọra \& Oliveira (2000) e Paula (1995), não reduzem sua discussão à violência física. Orientam sua abordagem para comprometimentos na saúde mental das mulheres. Isso significa que não tratam especificamente dos maus-tratos psicológicos, mas procuram alertar para os agravos que vão além das marcas corporais.

Corrêa (2000), Schraiber e colaboradores (2000) e Suárez e colaboradores (1999), que abordam a violência no serviço pré-natal, indicam o aborto espontâneo como conseqüência da violência dirigida à mulher. Suárez, Machado \& Bandeira (1999), além de observarem que a mulher vitimizada tem um risco de aborto espontâneo duas vezes maior do que a não vitimizada, alertam que, como conseqüência da violência, pode haver nascimento precoce de crianças, com peso abaixo da média e/ou com seqüelas somáticas e deformações físicas.

Schraiber e colaboradores (2000) e Xavier (1999) fazem uma discussão sobre a associação de violência contra a mulher e a fatores de risco a DST/HIV/Aids. Fica subentendido que, quando abordam tal associação, estão se referindo à violência sexual, em específico.

Especificamente em relação à saúde mental, identificam-se três situações. Há autores, a exemplo de Tavares (2000), que refletem acerca de 
situações que causam agravos psicológicos. Dentre elas, destacam-se abandono, insulto, calúnia e ameaça. Outros centram sua discussão nos sinais e sintomas dos comprometimentos psicológicos, principalmente no que se refere à depressão e a medos constantes (Corrêa, 2000; Cardoso, 1996). Em relação aos agravos psicológicos causados pela violência, Cardoso (1996) e Tavares (2000) destacam o comprometimento da auto-estima da mulher derivado de ações violentas a ela dirigida.

Também destacam-se aqueles autores que enfocam a violência como causa de mortalidade (Albuquerque et al., 1998; Noronha \& Daltro, 1991). Esses autores discutem causas de mortalidade, focalizando as causas externas e aí inserindo a questão da violência em relação à mulher.

Sobre a relação violência-mulher-saúde, é digno de nota um artigo (Santos, 1997a) que discute o assédio sexual praticado por médico contra cliente, no espaço do consultório. Embora apenas uma fonte traga esse problema, ela alerta, a partir de dados concretos, para a possibilidade de, no espaço da saúde, local em que se deveria prevenir a violência, a mulher também ser violentada.

A análise também revela que há autores que registram o fato de o campo da saúde ou ainda não dar a devida atenção aos casos de mulheres em situação de violência ou não abordar adequadamente tais casos. Na atenção às mulheres, nos serviços de saúde parece que ainda há uma 'invisibilidade da violência' (Schraiber et al., 2000) e uma certa 'surdez' em atender aos apelos das mulheres que vivenciam situações de violência (Deslandes et al., 2000).

Além dessa crítica mais generalizada, um autor observa que a violência de trânsito e a violência interpessoal, apesar de serem causas de um grande número de óbitos, não conseguem chamar a atenção das autoridades de saúde (Faundes et al., 2000).

Schraiber e D'Oliveira (1999) observam que a área da saúde, em geral, não considera os sofrimentos das mulheres em situação de violência como doença, a não ser que tais sofrimentos tenham uma base anatomopatológica. Por outro lado, se essa área considera a violência como patologia, pode reduzir 'ao corpo individual aquilo que é por definição das interações humanas'.

Em decorrência ou não da crítica feita à abordagem do campo da saúde em relação à temática em estudo, há autores que tecem considerações acerca de aspectos de prevenção relacionados a ela. Em geral, são aspectos pontuais que aparecem nas considerações finais de seus respectivos trabalhos. 
Sintetizando as questões de prevenção, pode-se classificá-las da seguinte forma: alerta para a necessidade de o setor da saúde participar de ações que vão para além dele; indicações voltadas para a capacitação dos profissionais de saúde; e recomendações para os serviços de saúde.

No plano mais geral da sociedade, há autores que propõem que o campo da saúde se articule a outras instituições para que sejam promovidas ações voltadas para:

- a compreensão das raízes socioculturais do jogo de poder que cerca as relações de gênero e a prática da sexualidade (Cardoso, 1996; Suárez et al. 1999);

- o combate às causas dos conflitos e a solução para os problemas, assegurando a qualidade de vida das pessoas no sentido de melhorar as relações interpessoais (Cabral, 1999; Schraiber \& D'Oliveira, 1999);

- o desenvolvimento de uma rede social de apoio e de serviços de assistência integral a mulheres em situações de violência (Cardoso, 1996; Jong, 2000; Moreira, 1999).

No que se refere à capacitação de profissionais da saúde, destacam-se propostas de ações para que tais profissionais:

- mudem suas atitudes e preconceitos diante da violência que ocorre nas relações conjugais (Paula, 1995);

- não reduzam a atenção às demandas que emergem da violência à ótica biomédica (Corrêa, 2000; Schraiber \& D’Oliveira, 1999);

- possam melhor diagnosticar a ocorrência da violência (Bergamo, 1998).

Aos serviços de saúde, os autores propõem que:

- promovam condições para que possam emergir os casos de mulheres em situação de violência (Schraiber et al., 2000);

- repensem o seu papel ético-político diante das mudanças nas relações de gênero, bem como o seu papel na manutenção da desigualdade ou na construção de novas formas de poder para propiciar a redução da violência, dentro e fora de seu espaço (D'Oliveira, 1996);

- não só prestem uma atenção clínica e cirúrgica de qualidade, mas também sejam capazes de desencadear ações preventivas (Deslandes et al., 2000);

- acolham, com respeito e sigilo estrito, as mulheres em situação de violência e desenvolvam uma abordagem de cuidados própria a elas (Schraiber \& D'Oliveira, 1999; Schraiber et al., 2000); 
- não reduzam a atenção às mulheres em situação de violência à dimensão da doença ou do risco em saúde (Schraiber \& D'Oliveira, 1999).

Propiciando-se o diálogo dessas medidas de prevenção com as que o Ministério da Saúde preconiza, encontram-se alguns pontos de interseção e aspectos que as nossas fontes analisadas não contemplaram. Para o Ministério da Saúde, as unidades de saúde deveriam:

- promover a organização de grupos de mulheres com a finalidade de trabalhar as questōes de gênero, poder, violência, fortalecimento da autonomia e formas alternativas de resolução de conflitos;

- facilitar o acesso a uma rede de apoio social (trabalho, moradia etc.), buscando incluir a mulher e elevar sua condição de cidadania;

- promover grupos de homens com a finalidade de propiciar a discussão sobre a violência, relações de gênero, fortalecimento da auto-estima e formas alternativas de resolução de conflitos (Brasil, 2001, p. 54).

A Organização Pan-americana de Saúde também vem desenvolvendo projeto que enfoca a violência intrafamiliar. Através desse projeto, busca, em nível local, incentivar a criação de redes comunitárias compostas por diversos setores para o desenvolvimento de uma proposta coordenada em torno da violência doméstica. Já em nível nacional, o projeto procura fomentar a implantação de políticas e normas legais que apóiem as instituições no enfrentamento do problema. Também no âmbito dos meios de comunicação, o referido projeto vem atuando no sentido de difundir a não-aceitação da violência contra a mulher (Hartigan, 1997).

Nessas medidas preventivas, podem-se identificar alguns aspectos que, segundo nosso ponto de vista, constituem-se em avanços na forma de abordar-se a temática. A indicação de que as ações do campo da saúde devem ser articuladas com outros setores da sociedade e a inclusão de ações que possibilitem a discussão entre homens e mulheres acerca de situações violentas como forma de se preservar a saúde são exemplos desses avanços.

\section{Consideraçōes Finais}

Ao final desta análise, podem-se pontuar aspectos fundamentais para que a discussão da temática continue se desenvolvendo no sentido de melhor abordar a mulher em situações de violência. Alguns desses aspectos encontram-se mais trabalhados do que outros na literatura nacional. 
No entanto, mesmo que o estado da arte apresentado na produção ainda precise avançar, considera-se importante demarcar alguns pontos.

A preocupação de se fazer uma crítica acerca da abordagem que o campo da saúde deve buscar para o problema é um avanço que se destaca na década de 90 . Essa abordagem, que não deve se reduzir à ótica biomédica, nem tampouco ao enfoque epidemiológico, é um desafio a ser vencido pelos profissionais da saúde. O alerta já foi dado. Falta o 'como' fazer isso de forma que, ao mesmo tempo, se consiga atender a demandas específicas e promover uma compreensão mais ampla sobre tais especificidades.

Outro avanço que as fontes analisadas indicam refere-se à reflexão que procura, ainda que timidamente, deslocar-se da redução da mulher como 'objeto' da violência - traduzida no olhar exclusivo da vitimização para o debate da promoção da saúde dos 'sujeitos' diante de situações de violência, vistas a partir de uma dimensão relacional de gênero.

Destaca-se, por último, um princípio de estratégia para enfrentamento do problema em questão que pode ser inferido a partir da análise das fontes estudadas. Esse princípio refere-se ao fato de que não há um ordenamento hierárquico de ações a serem promovidas, nem tampouco um setor a ser priorizado e/ou alçado à categoria de líder. Todas as frentes de ações e todos os espaços institucionais, aí incluídos os da saúde, podem trazer contribuições. Essa contribuição pode se tornar realidade desde que se consiga ampliar o foco e articular a instância dos conhecimentos.

\section{REFERÊNCIAS BIBLIOGRÁFICAS}

ALBUQUERQUE, R. M. et al. Causas e fatores associados à mortalidade de mulheres em idade reprodutiva em Recife, Brasil. Cadernos de Saúde Pública, 14 (supl. 1): 41-48, 1998.

ALMEIDA, R. O. Mulheres que matam. Rio de Janeiro: Relume Dumará, 2001.

BANDEIRA, L. Um recorrido pelas estatísticas da violência sexual no Distrito Federal. In: SUÁREZ, M. \& BANDEIRA, L. (org.). Violência, gênero e crime no Distrito Federal. Brasília: Paralelo 15/ Editora UnB, 1999. p. $431-496$.

BEISSMAN, D. M. Estudo psico-social de homens agressores de mulheres notificados na Delegacia da Mulher de Campinas/SP, 1994. Dissertação de Mestrado. Campinas: Faculdade de Ciências Médicas, Universidade Estadual de Campinas. 
BERGAMO, W. Perfil da vítima de estupro em cidades de pequeno porte do estado de São Paulo, 1998. Dissertação de Mestrado. São Paulo: Escola Paulista de Medicina, Universidade Federal de São Paulo.

BOULDING, E. Las mujeres y la violencia social. In: UNESCO. La Violencia y sus Causas. p. 265-275, 1981.

BOURDIEU, P. Conferência do prêmio Goffman: a dominação masculina revisitada. In: LINS, D. (org.). A dominação masculina revisitada. Campinas: Papirus, 1998. p. 11-27.

BOURDIEU, P. A dominação masculina. Rio de Janeiro: Bertrand Brasil, 1999.

BOURDIEU, P. Meditações pascalianas. Rio de Janeiro: Bertrand Brasil, 2001.

BRAGHINI, L. Cenas repetitivas de violência doméstica: um impasse entre Eros e Tanatos. Campinas: Editora Unicamp, 2000. (Coleção Teses).

BRASIL. Ministério da Saúde. Violência intrafamiliar: orientaçōes para práticas em serviço. Brasília: Secretaria de Políticas de Saúde - Ministério da Saúde, 2001.

BUVINIC, M; MORRISON, A. R. \& SHIFTER, M. Violência nas Américas: um plano de ação. In: MORRISON, A. R. \& BIEHL, M. L. (org.). A família ameaçada: violência doméstica nas Américas. Rio de Janeiro: Editora FGV, 2000. p. 19-48.

CABRAL, M. A. A. Prevenção da violência conjugal contra a mulher. Ciência E Saúde Coletiva, 4: 183-191, 1999.

CAMPOS, J. R.; NASCIMENTO, L. G. do \& ALMEIDA JÚNIOR, W. J. de. Violência sexual em Belo Horizonte: pesquisa no Instituto Médico Legal. Jornal Brasileiro de Ginecologia , 7 (104): 22 1-230, 1994.

CARDOSO, N. M. B. Mulheres em situação de violência conjugal: incidência, conceitos, fatores associados e conseqüências da violência. Barbarói, 4/ 5: 69-80, 1996.

COHEN, C. \& MATSUDA, N. E. Crimes sexuais e sexologia forense: estudo analítico. Revista Paulista de Medicina, 4 (109): 157-164, 1991.

CONSTANTINO, P. Entre as escolhas e os riscos possiveis - a inserção das adolescentes no tráfico de drogas, 2001. Dissertação de Mestrado. Rio de Janeiro: Escola Nacional de Saúde Pública, Fundação Oswaldo Cruz.

CORRÊA, M. S. M. Vivência de mulheres em condições de violência conjugal, 2000. Dissertação de Mestrado. Salvador: Escola de Enfermagem, Universidade Federal da Bahia. 
D'OLIVEIRA, A. F. P. L. Gênero e violência nas práticas de saúde: contribuição ao estudo da atenção integral à saúde da mulher, 1996. Dissertação de Mestrado. São Paulo: Faculdade de Medicina, Universidade de São Paulo.

D'OliveirA, A. F. P. L. \& SCHRAIBER, L. B. Violência de gênero, saúde reprodutiva e serviços. In: GIFFIN, K. \& COSTA, S. H., Questōes da saúde reprodutiva. Rio de Janeiro: Editora Fiocruz, 1999. p. 337355 .

DESLANDES, S. F.; GOMES, R. \& SILVA, C. M. F. P. Caracterização dos casos de violência doméstica contra a mulher atendidos em dois hospitais públicos do Rio de Janeiro. Cadernos de Saúde Pública, 16 (1): 129-137, 2000.

FAUNDES, A.; PARPINELLI, M. A. \& CECATTI, J. G. Mortalidade de mulheres em idade fértil em Campinas, São Paulo (1985-1994). Cadernos de Saúde Pública, 16 (3): 671-679, 2000.

GIFFIN, K. Violência de gênero, sexualidade e saúde. Cadernos de Saúde Pública, 10 (supl. 1): 146-155, 1994.

GOMES, R.; MINAYO, M. C. S. \& FONTOURA, M. H. A. A prostituição infantil sob a ótica da sociedade e da saúde. Revista Saúde Pública, 33(2): $171-179,1999$.

GROSSI, P. K. \& AGUINSKI, B. G. Por uma nova ótica e uma nova ética na abordagem da violência contra mulheres nas relaçōes conjugais. In: GROSSI, P. K. \& WERBA, G. C. (org.). Violência de gênero: coisas que a gente não gosta de saber. Porto Alegre: EDIPUCRS, 2001. p. 19-45.

HARTIGAN, P. La OPS enfoca el problema de la violencia contra la mujer. Revista Panamericana de Salud Publica, 2 (4): 290- 294, 1997.

HEISE, L.; PITANGUY, J. \& GERMAIN, A. Violence against Women: The Hidden health Burden. Washington, D. C.: The World Bank, 1994.

JONG, L. C. Perfil epidemiológico da violência doméstica contra a mulher em cidade do interior paulista, 2000. Dissertação de Mestrado. São Paulo: Faculdade de Saúde Pública, Universidade de São Paulo.

KANTORSKI, L. P.; MOREIRA, A. F. \& LUZ, H. B. da. Representação da violência contra a mulher: sob o olhar dos sujeitos que atuam na Delegacia de Mulheres. Texto Contexto Enfermagem. 6 (1): 33-49, 1997.

LEITAO, G. da C. M. Crenças argumentais de mulheres que sofreram agressōes de seus maridos ou companheiros: estudo comparativo no campo da análise 
transacional, realizado com populaçōes atendidas na $2^{\underline{a}}$ Delegacia de Polícia de Defesa da Mulher e no Centro de São Paulo, 1991. Tese de Doutorado. São Paulo: Faculdade de Saúde Pública, Universidade de São Paulo.

LEITE, E. de P. A dupla condenação de prisioneiras na cadeia: um invisível objeto da saúde coletitıa, 1999. Dissertação de Mestrado. São Paulo: Escola de Enfermagem, Universidade de São Paulo.

MARTINS, P. H. Paixões avassaladoras: violência e intimidade. Percurso Revista de Psicanálise, 18 (1): 65-77, 1997.

MENEGHEL, S. N. et al. Mulheres cuidando de mulheres: um estudo sobre a Casa de Apoio Viva Maria, Porto Alegre, Rio Grande do Sul, Brasil. Cadernos de Saúde Pública, 16 (3): 747-757, 2000.

MOREIRA, V. M. Grupo de encontro com mulheres vítimas de violência intrafamiliar. Estudos de Psicologia, 4 (1): 61-77, 1999.

MOURA, M. A. V. \& OLIVEIRA, P. R. F. A percepção das mulheres vítimas de lesão corporal dolosa. Escola Anna Nery - Revista de Enfermagem, 4 (2): 257-267, 2000.

NORONHA, C. V. \& DALTRO, M. E. A violência masculina é dirigida para Eva ou Maria? Cadernos de Saúde Publica, 7( 2): 215-23 1, 1991.

PAULA, R. F. de Fatores predisponentes para violência física contra esposas. Neurobiologia, 2 (58): 57-64, 1995.

PRIANTE, P. S. B. Perfil da violência sexual contra mulheres no município de Belém do Pará, 2000. Dissertação de Mestrado. São Paulo: Escola Paulista de Medicina, Universidade Federal de São Paulo.

REICHENHEIM, M. E.; MORAES, C. L. \& HASSELMANN, M. H. Equivalência semântica da versão em português do instrumento Abuse Assessment Screen para rastrear a violência contra a mulher grávida. Revista de Saúde Pública, 34 (6): 610-616, 2000.

SAFFIOTI, H. I. B. Violência contra a mulher e violência doméstica. In: BRUSCHINI, C. \& UNBEHAUM, S. G. (org). Gênero, democracia e sociedade brasileira. São Paulo: Fundação Carlos Chagas/Editora 34, 2002. p. 321-338.

SANTOS, J. C. dos. Assédio sexual no consultório. Revista Brasileira de Medicina Psicossomática, 1 (2): 103-105, 1997.

SANTOS, M. de F. F. dos. Violência sexual contra a mulher cometida por agressor desconhecido da vítima, 1997. Dissertação de Mestrado, Campinas: Instituto de Psicologia, Pontifícia Universidade Católica de Campinas. 
SANTOS, D. M. dos. Violência institucional em serviço de saúde: representaçōes sociais de mulheres em processo de parturição, 2000. Dissertação de Mestrado. Salvador: Universidade Federal da Bahia.

SCHRAIBER, L. B. \& D'OLIVEIRA, A. F. P. L. Violência contra mulheres: interfaces com a saúde. Interface - Comunicação, Saúde, Educação, 3 (5): $11-26,1999$.

SCHRAIBER, L. B. et al. A violência contra mulheres: demandas espontâneas e busca ativa em unidade básica de saúde. Saúde e Sociedade, 9 (1/2): 3-5, 2000.

SIMÃO, M. O. et al. Alcoolismo feminino: revisão de aspectos relacionados à violência. Revista $A B P-A P A L, 19$ (4): 139-148, 1997.

SOUZA, E. R. \& MINAYO, M. C. S. Análise das tendências da produçāo acadêmica sobre violência e acidentes. Relatório de Pesquisa. Rio de Janeiro: Claves/Esnp/Fiocruz-Cnpq, 2001.

SUÁREZ, M. \& BANDEIRA, L. A politização da violência contra a mulher e o fortalecimento da cidadania. In: BRUSCHINI, C. \& UNBEHAUM, S. G. (orgs.). Gênero, democracia e sociedade brasileira. São Paulo: Fundação Carlos Chagas/Editora 34, 2002. p. 295-320.

SUÁREZ, M.; MACHADO, L. Z. \& BANDEIRA, L. M. Violência, sexualidade e saúde reprodutiva. In: GALVÃO, L. \& DIAZ, J. (orgs.). Saúde sexual e reprodutiva no Brasil. São Paulo: Editora Hucitec; Brasília: Population Council, 1999. p. 277-309.

TAVARES, D. M. C. Violência doméstica: uma questão de saúde pública, 2000. Dissertação de Mestrado. São Paulo: Faculdade de Saúde Pública, Universidade de São Paulo.

TETELBOM, M. et al. Abuso sexual intrafamiliar: um alerta. Jornal Brasileiro de Psiquiatria, 40 (3): 145-148, 1991.

TUESTA, A. de V. A. Gênero e violência no âmbito doméstico: a perspectiva dos profissionais de Saúde, 1997. Dissertação de Mestrado. Rio de Janeiro: Escola Nacional de Saúde Pública, Fiocruz.

VICENTE, R. A. G. Ruim com ele, pior sem ele? Uma investigação com mulheres vítimas de violência, 1999. Dissertação de Mestrado. São Paulo: Psicologia Clínica, Universidade Católica de São Paulo.

VIGARELLO, G. História do estupro: violência sexual nos séculos XVI-XX. Rio de Janeiro: Jorge Zahar Editora, 1998.

XAVIER, I. de M. Violência de gênero presente na relação mulher e Aids: olhar da enfermeira. Revista de Enfermagem da UERJ, 7 (1): 14-18, 1999. 